\section{Stereoscopic Photography}

IN "A Note on Stereoscopic Photography"1 Dr. John R. Baker refers to different methods of making stereoscopic photographs of near objects. There are two possibilities : the axes of the cameras can be parallel to each other, or they can be convergent to the object. Dr. Baker concludes : "The convergent camera gives the proper representation of the object". I think this conclusion is not right. Let us consider a moment a photograph made by a camera in an arbitrary position. It always represents reality if we look at it in the right manner. It is necessary to put the eye in the place occupied by the lens in making the photograph, and the different points of the image will be seen under the same angles as the correspond. ing points of the object. In Fig. 1 of Dr. Baker's article both photographs have to be seen from $D$ and so $A^{\prime}$ and $A^{\prime \prime}, B^{\prime}$ and $B^{\prime \prime}$, and $C^{\prime}$ and $C^{\prime \prime}$ are seen in the same direction.

In choosing the right lenses for the stereoscope, it is possible to look at both photographs in the right manner. So each eye gets the same impression it should get in reality, and there is only left the possibility that both eyes, in looking to some detail, should have a position to each other different from that which they should have in reality. It is here there is a real difference between both methods. With convergent cameras we get the images of the object in the centre of the plate and in looking at them in the stereoscope the axes of the eyes will be parallel. With parallel cameras the images come more to the border, and in looking at them the axes of the eyes will be convergent. Here the effect of the parallel cameras is more according to reality, but the eyes are very insensitive to the difference. So the impression is the same in both circumstances.

It may be mentioned that one real advantage of the method of convergent cameras is a relatively big field of view, as only the common field of view of both cameras contributes to the stereoscopic impression.

\section{J. VAN ZUYLEN.}

Utrecht.

NATURE, 136, 193; August 3, 1935.

IN looking at a near object, the eyes are turned inwards. Therefore to procure a really natural stereoscopic view of two photographs of a near object, the eyes should be turned inwards at the same angle. To achieve this, the two photographs should be mounted in such a way that the correspond. ing points in them are nearer than the interpupillary distance. With this arrangement, it is true that proper stereoscopic views may be obtained with photographs of near objects taken with parallel cameras ; but if the corresponding points in the two photographs are separated by approximately the interpupillary distance (as in normal stereoscopic photography), a wrong impression is conveyed to the eyes.

Convergent vision with the stereoscope presents two difficulties. First, most people (as I have found by painful experience at conversaziones) are unable to fuse the images with a convergent stereoscope: when a person holds a stereoscope to his eyes, he reflexly directs his eyes for parallel vision. Secondly, the placing of the corresponding points in the two photographs nearer together than the interpupillary distance narrows the possible field of view.
For these reasons I nowadays keep to the standard stereoscope and use parallel vision, insisting only that to each eye there shall be presented exactly the view that would be obtained if one were looking at the object with one's eyes in the positions of the lenses of the cameras when the photographs were taken. This can only be achieved by using convergent cameras (or by using the equivalent, the tilting stage method, in stereo-photomicrography).

If the convergent stereoscope did not present the two disadvantages mentioned above, the ideal method for the stereoscopic photography of near objects would be the following. The photographs would be taken by convergent cameras (or by the use of the tilting stage). A convergent stereoscope would be used for viewing, and the two photographs would be arranged in the stereoscope in two different planes at right angles to the two lines of vision.

I wish to acknowledge the benefit of discussions on this subject with Prof. F. A. Lindemann and Mr. S. J. Baker.

\section{University Museum,}

JOHN R. BAKER.

Oxford.

Sept. 2.

\section{Raman Spectrum of Heavy Water}

THE Raman spectrum of heavy water was first studied by Prof. R. W. Wood ${ }^{1}$, who obtained a strong band at $2517 \mathrm{~cm} .^{-1}$. For the vapour of heavy water, Rank, Larsen and Bordner ${ }^{2}$ found a line at $2666 \mathrm{~cm}^{-1}$, while Wood has reported a line at $2601 \mathrm{~cm}^{-1}$. These results are evidently incomplete. In view of the great interest attached to this substance, it appeared worth while to re-examine the matter, using $50 \mathrm{gm}$. of $99 \cdot 2 \mathrm{gm} . / 100 \mathrm{gm} . \mathrm{D}_{2} \mathrm{O}\left\langle d_{4}^{20}\right.$ 1.1049) supplied by the Norsk Hydro-Elektrisk Kvaelstofaktieselskab. The Raman spectrum of the substance was photographed with a Hilger twoprism spectrograph with about 72 hours exposure, and is reproduced as Fig. 1.

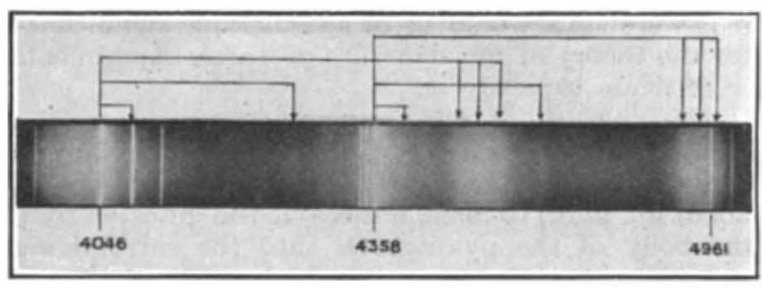

FIG. 1. Raman spectrum of heavy water.

The spectrum shows a number of interesting features which have not been noticed by the previous workers.

1. The principal band is seen to consist of three imperfectly resolved components of frequency shifts $2646 \mathrm{~cm}^{-1}, 2500 \mathrm{~cm} .^{-1}$ and $2366 \mathrm{~cm}^{-1}$. These correspond to the components $3630 \mathrm{~cm} \cdot .^{-1}, 3435 \mathrm{~cm} \cdot .^{-1}$ and $3200 \mathrm{~cm}^{-1}$ reported for ordinary water, and indicate that heavy water is polymerised in a very similar way to ordinary water.

2. A new band with a frequency shift of $1231 \mathrm{~cm}^{-1}$ is very clearly seen with both the $4358 \mathrm{~A}$. and $4046 \mathrm{~A}$. excitations. Careful examination of the plate reveals faint components to this on either side, the central component of the triplet being by far the brightest. The position of this band compares 